\title{
Use of electricity and malaria occurrence: is there a link? The case of Malawi
}

\author{
Luca Tasciotti \\ a International Institute of Social Studies, Kortenaerkade 12, The Hague, The Netherlands \\ ${ }^{b}$ School of Oriental and African Studies, Russell Square, London WC1H 0XG, United Kingdom \\ Abstract
}

Sub-Saharan countries are facing a number of similar challenges, including their need to increase electricity access for both urban and rural dwellers and to limit the cases of malaria related morbidity and mortality.

This study explores the link between using electricity, for either lighting or cooking purposes, and the occurrence of malaria cases using country-representative household level data for Malawi.

The descriptive statistics and the econometric results highlight the fact that those household members living in 'electrified' households are more likely to experience malaria. The interpretations behind those results can be diverse; as evidence suggests, malaria vectors are attracted by electric lights and outdoor lighting available after the sunset may change people habits and increases their exposure to those vectors.

This study aims at raising the attention to a nexus which has very rarely been studied theoretically and even less empirically, despite the fact that electricity projects are now in the agenda of several Sub-Saharan countries and that malaria still continue to constitute a major threat for an incredible high number of people, most of all children and pregnant women.

Keywords: electrification; malaria; household data; Malawi; household analysis. 
This is the version of the article accepted for publication in Energy Policy Vol. 101, 310-316 published by Elsevier available at: http://dx.doi.org/10.1016/j.enpol.2016.10.028

Accepted version made available under CC-BY-NC-ND 4.0 License from SOAS Research Online:

https://eprints.soas.ac.uk/23437/

\section{Introduction}

Electricity is considered to be a condition sine-qua-non needed for improving several aspects of everyone's life and for promoting the economic development of a given country (World Bank, 2008). Still, the electrification rate of many Sub-Saharan African countries is relatively low, between 30 and $64 \%$ in urban areas and even less in rural areas where the share of the population having access to electricity is as low as $10 \%$ (IEA, 2014). This last decade has witnessed an increase in the share of urban and rural dwellings being electrified thanks to the proliferation of electrification projects in several developing and transition economies in Africa, Asia and Latin America (Kaygusuz, 2012). ${ }^{1}$

The full spectrum of spillover effects stemming from the availability and the use of electricity is still being investigated and it would be difficult to enumerate and rank them without taking into consideration the specificity of a country and a number of micro and macro indicators related to it (Pellegrini and Tasciotti, 2012). In a nutshell, the use of electricity for both cooking and lighting purposes may bring the household a number of benefits -from saving time otherwise spent collecting firewood and cooking using firewood to increased study time for children in schooling age, from greater security to extended hours for businesses to be open. In addition, electricity allows the household to have access to media devices -television and radio- with that generating a number of benefits for all the household members -greater awareness, access to news and

\footnotetext{
${ }^{1}$ For more information on the electrification projects which have been undergoing in the last few years, please refer to the following websites. Please consider that the list is not exhaustive of the whole spectrum of project available in developing countries. http://www.minbuza.nl/en/Key_Topics/Development_Cooperation for rural electrification projects in Africa and Asia. See http://www.fres.nl/ for projects undergoing in South Africa, Mali and Burkina Faso. See http://www.lightingafrica.org/ for the 'Lighting Africa' project. The project's longer-term goal is to eliminate market barriers for the private sector and to reach 250 million people in Africa without electricity, and using fuel based lighting, by 2030.
} 
This is the version of the article accepted for publication in Energy Policy Vol. 101, 310-316 published by Elsevier available at: http://dx.doi.org/10.1016/j.enpol.2016.10.028

Accepted version made available under CC-BY-NC-ND 4.0 License from SOAS Research Online:

https://eprints.soas.ac.uk/23437/

lower fertility rate among others (Grimm et al., 2015). The consequences of using cleaner sources of energy, especially for cooking, are significant for both children and adults' health and it translates into a decrease in the occurrence of respiratory diseases and eye infections (Aman et al., 2015).

While the positive households impacts related to the use of electricity are here acknowledged beforehand, this study aims at pointing out a potential negative impact by exploring the link between the use of electricity and the incidence of malaria at the household-member level. This study looks at the case of Malawi where the incidence of malaria is still extremely high with the entire population being at risk, 775 thousand suspected malaria cases in 2010 and 400 malaria attributed deaths in the same year (WHO, 2012). At the same time, current electrification rate in Malawi is still relatively low with $37 \%$ of the household being connected to the grid or using solar panel in urban areas and $2 \%$ in rural ones (IEA, 2014) even though the share of 'electrified' dwellings is believed to increase in the near future (Kaygusuz, 2012).

The link between the use of electricity and malaria occurrence is not extremely easy to disentangle even though there are few available studies pointing out the mechanisms through which this relation may occur. There are at least four reasons to believe that the use of electricity may impact the incidence of malaria. First of all, artificial light is a powerful insect attractant and evidence suggests that light traps are used by both entomologists and epidemiologists to capture insects (Barghini and de Medeiros, 2010). Second, electricity -as well as gas- used for cooking purposes replaces biomass thus eliminating the amount of indoor smoke which results in a substantially improved indoor air quality on one side and in an increased density of malaria vectors which, now, are not repelled by the smoke (Dube et al., 2012). Third, the availability of artificial light may alter the lifestyle of any community as, for 
This is the version of the article accepted for publication in Energy Policy Vol. 101, 310-316 published by Elsevier available at: http://dx.doi.org/10.1016/j.enpol.2016.10.028

Accepted version made available under CC-BY-NC-ND 4.0 License from SOAS Research Online:

https://eprints.soas.ac.uk/23437/

instance, night lighting increases outdoor activities and people's exposure to malaria vectors (Taylor, 1997). Lastly, electricity gives the household the possibility to access to mass media devices -television and radio above all- and hence to anti-malaria campaigns (Grimm et al., 2015). It is important to keep in mind than the four channels may affect different household members in distinct ways; as an example, women are believed to spend more time cooking, hence the lack of smoke and the increased presence of malaria vectors in the kitchen may affect women more than men. Likewise, men may spend more time outside the house with artificial lights available in the streets after the sunset. In this context, the effects electricity may have in terms of malaria occurrence is not only a matter of theoretical hypothesis but also a matter of empirical measurements for the household as a whole and for all its members.

A correct understanding of the malaria transmission channels is crucial to limit and possibly stop malaria occurrence. From an historical point of view, diseases caused by parasites have affected the humankind for several millennia and, to date, they still represent a major global threat for the world and for the poorest strata of the populations. Such diseases constitutes a barrier for human health and for the economic development of the country people live in (WHO, 2012). Malaria, which has been on the face of the earth for as long as we know, is a mosquito-borne disease caused by single-cell parasites which, invading the red blood cells, are responsible for high fever, and, lastly, for brain damage and death (Kilpatrick and Randolph, 2012). Nowadays there are more than 3.4 billion people at risk of contracting malaria, with the majority of them living in the most vulnerable and less developed areas of the globe; about 450 thousand people, predominantly children and pregnant women, die each year for malaria related cause (Zhou, 2015). Due to the severity that malaria still has in terms of morbidity and mortality, the 2015 Nobel Prize in Medicine has been assigned to 'Youyou Tu for her discoveries concerning a novel 
This is the version of the article accepted for publication in Energy Policy Vol. 101, 310-316 published by Elsevier available at: http://dx.doi.org/10.1016/j.enpol.2016.10.028

Accepted version made available under CC-BY-NC-ND 4.0 License from SOAS Research Online:

https://eprints.soas.ac.uk/23437/

therapy against Malaria' and for having 'developed therapies that have revolutionized the treatment of some of the most devastating parasitic diseases'.

The objective of this study is to assess whether the nexus between using electricity, for either lighting or cooking purposes, and the occurrence of malaria exists and which is the sign and the magnitude of this relation. This study uses a country-representative household level data representative of both urban and rural Malawi. Both the descriptive analysis and the econometric results suggest the fact that those urban and rural household members living in 'electrified' dwellings are more likely to experience malaria. The interpretations behind those results are multiple: malaria vectors are attracted by electric lights and outdoor lighting available after the sunset changes people habits and increases their exposure to those vectors.

This study aims at raising the attention to a nexus which has seldom been studied empirically, despite the fact that electricity projects are now in the agenda of several Sub-Saharan countries; furthermore, malaria still constitutes a major threat for an incredible high number of people in several areas of the globe, with children and pregnant women being the ones at higher risk. The objective of this study is twofold: it advices development practioners as well as central and local government of those countries where electrification projects are taking place and malaria is still a threat to consider the implementation of anti-malaria strategies -e.g. anti-malaria campaign, free use of treated bed-nets, extensive use of repellant. In addition, this study advocates the collection of ad-hoc household level data with a particular focus on the type of energy used and the aimed at studying this link in several other countries where malaria is endemic.

The rest of this study is organized as it follows; Section 2 discusses the main studies on the topic electricity-malaria while Section 3 provides the readers with an overview of the electrification situation in Malawi and describes the severity of malaria in the country. Section 4 offers a brief 
This is the version of the article accepted for publication in Energy Policy Vol. 101, 310-316 published by Elsevier available at: http://dx.doi.org/10.1016/j.enpol.2016.10.028

Accepted version made available under CC-BY-NC-ND 4.0 License from SOAS Research Online:

https://eprints.soas.ac.uk/23437/

description of the household level data used and few descriptive statistics. The empirical strategies and econometric results are in Section 5 followed by the conclusions and the policy implications of the study.

\section{Is there a link between electricity and malaria? Evidence from the literature}

There is only anecdotal evidence on the possible link between the use of electricity and the occurrence of malaria among family members which clashes with the many findings about the links between electricity and the occurrence of the Chagas disease and the leishmaniasis. The Chagas disease is commonly transmitted to humans and other mammals by an insect vector whereas the Leishmaniasis is a disease caused by protozoan parasites that belong to the genus Leishmania and which is transmitted by the bite of certain species of sand fly. The occurrence of these two types of disease has proved to increase in electrified areas (please refer to Barghini and Medeiros, 2010, for a comprehensive list of studies on that topic).

According to the literature on malaria and to a more recent study which investigated on the existence of the very same nexus (Pellegrini and Tasciotti, 2015), malaria incidence (MI) is a phenomenon that can be directly linked to the amount of malaria vectors in one given area vector density- and to the exposure, which indicates the amount of time household members spend in places where malaria vectors are present (formula (1)).

(1) $\quad M I=f($ vector density, exposure)

\subsection{Vector Density}

There are several studies showing that mosquitoes are attracted to light and that malaria vectors are captured using light traps (Barghini and de Medeiros, 2010). This suggests that the 
This is the version of the article accepted for publication in Energy Policy Vol. 101, 310-316 published by Elsevier available at: http://dx.doi.org/10.1016/j.enpol.2016.10.028

Accepted version made available under CC-BY-NC-ND 4.0 License from SOAS Research Online:

https://eprints.soas.ac.uk/23437/

indoor use of lights after sunset can increase the overall density of malaria vectors, considering the fact that houses in Malawi and in many other developing countries may present multiple entry points for malaria vectors. Other examples regarding a positive correlation between vector density and electricity come from Yamamoto et al. (2010), who found how households living in Burkina Faso in electrified houses are recorded to have higher occurrence of malaria. Their result is related to the lack of smoke previously produced by biomass used for cooking purposes. Smoke is supposed to prevent insects from entering into the dwelling biting. A very similar result has been found in a study conducted in rural areas of Papua New Guinea (Paul et al., 1995) and Kenya (Seyoum et al., 2002). Those results are in line with the habits many communities living in rural areas have to use aromatic smokes in addition to wood smoke -i.e. traditional fumigants, to deter mosquitoes. In rural Gambia, tree bark combined with synthetic perfumes -locally known aschurai- reduced the number of mosquitoes entering in the room. Traditional fumigants in Sri Lanka are supposed to decrease malaria occurrence whereas in Thailand, a mixture of DEET -N,N-diethyl-meta-toluamide- and a paste made from a local tree, wood apple, was an effective mosquito repellant when applied to the skin.

The overall effect biomass smoke may have in terms of malaria vector density is still under debate; as suggested by Biran et al., 2007, biomass used inside the dwelling for cooking purpose may increase the concentration of malaria vectors as well as a consequence of house ventilation, aimed at reducing the level of indoor smoking, which also provides opportunities for malaria vectors to enter the house.

\subsection{Exposure}

The changes electrification may bring in someone's life can be multiple, may go in different directions and are very likely to be extremely difficult to disentangle; for what concerns the 
This is the version of the article accepted for publication in Energy Policy Vol. 101, 310-316 published by Elsevier available at: http://dx.doi.org/10.1016/j.enpol.2016.10.028

Accepted version made available under CC-BY-NC-ND 4.0 License from SOAS Research Online:

https://eprints.soas.ac.uk/23437/

impacts electricity use may have on malaria related matters, the evidence suggests that electricity allows household members to spend more time outside the house after the sunset artificial light may reduce people's perception of risk and may encourage them to spend more time outside the dwelling- when malaria vectors are more active (Barghini and de Medeiros, 2010). Other changes include social interactions and sport activities, which can now take place outside the dwelling and in the evening with artificial light and which see as main actors especially men and male children (Winther, 2011).

There is some evidence pointing out the fact that spending time outside the dwelling during the evening hours has caused an increase in the rate of malaria occurrence; studies have been conducted in the Salomon Islands (Taylor, 1997) and rural Vietnam and Peru (Erhart et al., 2004).

\section{Malaria incidence and electrification in Malawi}

Malaria and Malawi do share a common history; the country, located in the South-East Africa, has been ranked the poorest one in the entire globe in 2015 based on 2010-2014 GDP per capita (World Bank, 2015) and it has a population of about 16 million inhabitants, with an annual growth rate of $2.8 \%$ (NSO, 2009). For what concerns malaria, the disease represents the leading cause of morbidity and mortality in the country with pregnant women and children below 5 years old being the most vulnerable groups (Chitunhu and Musenge, 2015). 100\% of Malawi's population is at risk of malaria and the country presents a year-round malaria transmission risk with a peak during the rainy season, from November to April; malaria cases account for between 30 and $40 \%$ of all outpatient visits in health clinics (WHO, 2012). Starting from 2005, the country has slowly started to reduce malaria with the launch of the so-called 'National Malaria Control 
This is the version of the article accepted for publication in Energy Policy Vol. 101, 310-316 published by Elsevier available at: http://dx.doi.org/10.1016/j.enpol.2016.10.028

Accepted version made available under CC-BY-NC-ND 4.0 License from SOAS Research Online:

https://eprints.soas.ac.uk/23437/

Programme' (NMCP); the NMCP represents an attempt of combining several plans and programs aimed at increasing the use of insecticide-treated bed nets, indoor residual spraying and prompt treatments for pregnant women and for symptomatic uncomplicated malaria cases for which the parasitemia was confirmed. Despite all those efforts, the last years have been marked by a stationary trend in malaria incidence (Taylor, 2009).

While the country's GDP has grown slowly but steadily in the last decade -an average $7 \%$ yearly increase has been recorded since the beginning of the 21st century- the generation of electricity as well as its supply has been rather stagnant. According to the last data available, the overall electrification rate in Malawi is $10 \%$, with $37 \%(2 \%)$ of the urban (rural) population having access to electricity (NSO, 2009).

In the last years the country has tried to plan and to invest more in the supply of electricity given the fact that the future economic growth of the country highly depends on the long-term availability of various energy sources -electricity in primis- and that electricity demand has been growing at a very fast rate -between $6 \%$ and $8 \%$ per annum (GoM, 2010a). Furthermore, the inefficient and unsustainable use of biomass energy in Malawi is contributing to the environmental degradation with visible consequences consisting in a high degree of deforestation, desertification and soil erosion.

\section{Data description and summary statistics}

The analysis that follows draws on data coming from 'The Integrated Household Survey' (IHS), dated 2010, which constitutes one of the main instruments implemented by the Central Government of Malawi to monitor and evaluate the changing conditions of Malawian 
This is the version of the article accepted for publication in Energy Policy Vol. 101, 310-316 published by Elsevier available at: http://dx.doi.org/10.1016/j.enpol.2016.10.028

Accepted version made available under CC-BY-NC-ND 4.0 License from SOAS Research Online:

https://eprints.soas.ac.uk/23437/

households'. The IHS sampling strategy, based on the cartography from the 2008 Malawi Population and Housing Census, uses a stratified two-stage sample design to make the survey representative at both rural and urban level.

A total of 3,219 households living in rural $-74 \%$ - and urban areas $-26 \%$ have been interviewed, for a total of approximately 15 thousands household members. As for the questionnaire, the majority of the questions have been directed to the head of the households -e.g. condition of the housing, main source of energy for cooking and lighting, food and non-food consumption, information on assets, etc- while other questions were asked to each household member. In particular, questions related to the health status, which is widely used in this study, the use of bed nets and other questions directly or indirectly related to malaria have been asked at the individual household member level.

The main advantage of using a multi-purpose survey for a study as this one is the availability of a wide range of variables which can be used as controls in the econometric analysis. The fact that this study uses data regarding the occurrence of malaria using a multi purposes survey might throw some doubt on the quality of the health data. In particular, the household's members' awareness on a number of illnesses might not be very as good as expected. On the other hand, evidence suggests that malaria related data do represent the actual situation in the country with a very good approximation as several studies have pointed out that household's members, both male and female, know how to recognized malaria symptoms, how malaria is transmitted and which are the treatments when malaria is suspected (Nuwaha, 2002). The caveat each reader has to keep in mind is that the statistical significance of the descriptive statistics and that of the empirical analysis may decrease as a consequence of the possible measurement errors, even though the variable indicating the incidence of malaria among household's members takes into 
This is the version of the article accepted for publication in Energy Policy Vol. 101, 310-316 published by Elsevier available at: http://dx.doi.org/10.1016/j.enpol.2016.10.028

Accepted version made available under CC-BY-NC-ND 4.0 License from SOAS Research Online:

https://eprints.soas.ac.uk/23437/

account the diagnosis of a health practitioner -either a doctor or a nurse- meaning a very high degree of credibility.

A brief look at the data shows that the share of households using various sources of energy for either cooking or lighting varies according to where the household lives -urban and rural areasand to the wealth of the household. For what concerns the lighting source, electricity is used by the biggest share of the richer households living in both urban and rural areas; as the wealth decreases, electricity is replaced by paraffin -middle class households- and firewood -lowest income quintile. As for the cooking source, biomass is still used by the majority of households in urban and rural settings. The only difference between urban and rural dwellers is the use of electricity and charcoal for those wealthier households living in urban areas; a good $90 \%$ of rural households, disregarding their wealth status, are still depending on the use of firewood.

Table 1 gives the readers an insight on the shares and numbers of household members having had malaria in the last 2 weeks. The table presents both the statistics for those malaria cases which have not and which have been confirmed by a health practitioner. The first feature which is worth to be commented is that not all the malaria cases are later confirmed by a health practitioner; slightly less than half of all those cases when the household members think having malaria actually turns out to be a different health issue, mostly fever. This result is partially in contrast with a wide stream of literature pointing out that those living in malaria endemic countries know malaria symptoms -e.g. fever, headache, vomiting, diarrhea, weight loss and dehydration- and hence malaria with a very low degree of error (Kengeya-Kayondo et al., 2004). The second comment stemming out from the table is that the incidence of malaria increases with the wealth of the household; this trend does not mean that those living in richer households get malaria more often; it rather indicates that richer households use health 
This is the version of the article accepted for publication in Energy Policy Vol. 101, 310-316 published by Elsevier available at: http://dx.doi.org/10.1016/j.enpol.2016.10.028

Accepted version made available under CC-BY-NC-ND 4.0 License from SOAS Research Online:

https://eprints.soas.ac.uk/23437/

practitioners and report malaria occurrence more often than other households. This is one of the reasons why the great majority of malaria related statistics have to be taken with a grain of salt and why malaria trend and statistics are unfortunately never as accurate as the importance of the disease would require (WHO, 2012).

$<$ Table 1 about here>

The histograms in Figure 1 show the percentage of malaria cases depending on the source of lighting (cooking) used by the household. The figure indicates that using electricity for lighting is associated with a $16 \%$ rate of malaria incidence; to this respect, only using candles is associated to a similar rate of malaria occurrence (even though the number of households using candles is not that high to guarantee a certain level of robustness of the result). As for cooking, electricity is associated to almost $20 \%$ of malaria cases, higher if compared to the use of charcoal and firewood. These descriptive statistics, while per se insufficient to derive any significant causal link, suggest that the relationship between the use of electricity and the occurrence of malaria is definitely worth further investigation.

$<$ Figure 1 about here>

\section{Empirical strategy and main results}

This study explores the nexus between electricity use and malaria incidence by estimating several probit models. The dependent variable -occurrence of malaria at the individual level (household level)- takes the value ' 1 ' if the household member (anyone in the household) has been recorded to have had malaria in the past two weeks and ' 0 ' otherwise; all the models here presented have been estimated using cluster-adjusted standard errors, with the cluster unit being the household itself. 
This is the version of the article accepted for publication in Energy Policy Vol. 101, 310-316 published by Elsevier available at: http://dx.doi.org/10.1016/i.enpol.2016.10.028

Accepted version made available under CC-BY-NC-ND 4.0 License from SOAS Research Online:

https://eprints.soas.ac.uk/23437/

Despite the fact that the data used here had been collected for purposes different from malaria related objectives, in what follows all those households (not) using electricity, either for cooking or for lighting purposes, will be considered as the 'treated' (control) group. All the household members in the treatment group, as a consequence of using electricity as source of either cooking or lighting, are those considered to have higher change of either changing their lifestyles or to live in a dwelling with a higher density of malaria vectors. The size of the treatment and control groups in all the different models are highlighted in Table 2.

$<$ Table 2 about here $>$

A total of six probit models will be estimated; ${ }^{2}$ the models take the form expressed in formula (2) and (3) and will be estimated at the household level, household members level and only for women-model (2)- and for men only-model (3):

$$
\begin{aligned}
& \text { Malaria } \left._{i}=a_{0}+b_{1} \text { (electricity for cooking }\right)_{i}+b_{i} X_{i}+e_{0 i} \\
& \text { Malaria } \left._{i}=a_{0}+b_{1} \text { (electricity for lighting }\right)_{i}+b_{i} X_{i}+e_{0 i}
\end{aligned}
$$

where the dependent variable 'Malaria' indicates malaria cases at the household level, household members level and women or men level, all of them confirmed by a health practitioner. The independent variables includes the dummy 'electricity for cooking' ('electricity for lighting') and the ' $X$ ' vector which take into account of the i) income quintile, ii) whether the household lives in urban or rural areas, iii) household size, iv) age of the household member, v) highest education of the household head and whether the household head is capable to read English, vi) several controls for the type of dwelling the household live in (property house,

\footnotetext{
${ }^{2}$ Several other probit models have been estimated but the results have not been reported in this study; models (2) and (3) have been estimated using only urban or rural households, and taking into account only few districts of the country -those where electricity is mostly used. The results do not show trends particularly different from the one reported here.
} 
This is the version of the article accepted for publication in Energy Policy Vol. 101, 310-316 published by Elsevier available at: http://dx.doi.org/10.1016/j.enpol.2016.10.028

Accepted version made available under CC-BY-NC-ND 4.0 License from SOAS Research Online:

https://eprints.soas.ac.uk/23437/

material of the walls, material of the roof, type of toilet used, proximity of a source of water), vii) whether the household member use a treated bed-net, viii) asset variables referring to the household's ownership of television/radio, ix) geographical dummies. A list of all the variables used and their mean, standard deviation, maximum and minimum values are presented in Table 3.

$<$ Table 3 about here>

The choice of control variables relies on relations between individual household's characteristics and malaria incidence that have been identified in several existing studies (Lowe et al., 2013). The choice of the control variables used in model 1-6 relies on the evidence reported in existing studies. The income quintiles -considered as a proxy for the household's socio-economic statusmay influence a number of individual behaviors as well as affect households actions regarding anti-malaria strategies. Better-off households are more likely to adopt malaria prevention strategies -purchase bed-nets, having houses with no entry points for malaria vectors, etc...even though a number of studies point out that the nexus between income and malaria is positive but not significant (Worrall et al., 2005). The inclusion of the household size variable relates to the fact that households' members living in larger households are more likely to experience malaria (Huldén and McKitrick, 2013); larger households may not have the means to purchase bed nets for everyone and the sanitation system, positively related to the occurrence of the disease, may be poorer in larger households (Ajadi et al, 2012). Other demographic variables included in the models relate to the age of the household members and to the literacy level of the head of the household and his/her spouse. Older people have been found to be less likely to experience malaria (Kleinschmidt and Sharp, 2001) whereas the inclusion of the literacy variable is driven by the fact that literate household heads may be aware of the prevention 
This is the version of the article accepted for publication in Energy Policy Vol. 101, 310-316 published by Elsevier available at: http://dx.doi.org/10.1016/j.enpol.2016.10.028

Accepted version made available under CC-BY-NC-ND 4.0 License from SOAS Research Online:

https://eprints.soas.ac.uk/23437/

strategies to reduce the risk of malaria. All the variables related to the quality of the dwelling are included in the models as housing conditions can have an impact on malaria occurrence (Guthmann et al., 2001); poorly constructed houses -as well as houses built with cheap and nondurable materials and roofs constructed with traditional materials such as earth or thatch- are associated with an increased risk of malaria as they may provide access points for malaria vectors (Yamamoto, 2010). The type of toilet used may increase the risk of malaria if the toilet is not covered -as urine and feces attract mosquitoes. Being the owner of the dwelling will decrease the incidence of malaria as house owners usually take more care of their homes.

The use of repellent soaked bed nets will reduce malaria, whereas non-treated bed nets may not constitute an effective prevention tool as they wear quickly and they may have holes, which provide entry points for malaria vectors (Holtz et al., 2002; Kachur et al., 1999). Television and radio ownership are expected to decrease malaria incidence by increasing household's members awareness of malaria, its causes and consequences. Lastly, urban/rural as well as geographical dummies are included to prevent geographical factors and the way the electricity is distributed in different areas of the country to affect the results. The urban/rural dummy is needed here to capture the difference in malaria occurrence between urban and rural households, as existing evidence suggests that urban households are less likely to experience malaria. The density of malaria vectors is on average higher in rural areas, where the environment is more suitable for malaria vectors' reproduction. Furthermore, households living in urban areas are better-off than their rural counterparts -meaning better constructed houses, access to mass-media devices and availability of treated bed-nets. 
This is the version of the article accepted for publication in Energy Policy Vol. 101, 310-316 published by Elsevier available at: http://dx.doi.org/10.1016/j.enpol.2016.10.028

Accepted version made available under CC-BY-NC-ND 4.0 License from SOAS Research Online:

https://eprints.soas.ac.uk/23437/

The coefficients associated to the variable indicating the effects of using electricity for cooking or lighting are expressed in Table 4 which does not report the probit coefficients of all the other variables.

$<$ Table 4 about here>

Models 1, 2, 4 and 5 aim at looking the effect of using electricity for cooking and for lighting at the household level and at the household members' level; models 3 and 6 aim at measuring whether the effects of electricity on malaria cases are different for female (male) household members. Women (men) are the ones spending more time in the house (outside the house) and if electricity increases the density of malaria vectors indoor (if electric lights increase the time spent outside the house after the sunset) female (male) household members would be more likely to experience malaria.

The coefficient associated to the 'electricity for cooking' is positive and significant at $1 \%$ for the household level, the household members and the women model (coefficients of Model from 1 to 3). This means that using electricity for cooking purposes increases the occurrence of malaria cases for all the household members, in particular for the female members as they are the ones spending most of the time in the kitchen (the coefficient for Model 3 is higher than for the previous 2 models). Those results, which investigate on the vector density channel, are somehow not surprising and evidence what part of the literature of malaria occurrence has already highlighted; the use of 'clean' energy source, i.e. electricity, for cooking makes the air inside the dwelling/kitchen cleaner compared to the situation when biomass was used for cooking. Cleaner air has been proved to attract malaria vector more than polluted air with consequences in terms of likelihood of getting malaria (Biran et al., 2007). 
This is the version of the article accepted for publication in Energy Policy Vol. 101, 310-316 published by Elsevier available at: http://dx.doi.org/10.1016/j.enpol.2016.10.028

Accepted version made available under CC-BY-NC-ND 4.0 License from SOAS Research Online:

https://eprints.soas.ac.uk/23437/

Models 4 to 6 , on the other side, investigate on the effect that using electricity for lighting may have for malaria incidence. The first two models, 4 and 5, are estimated taking into accounts the households and all the household members while the last one, Model 6, only take into consideration the male part of the households. The reason for that lays into the fact that, as clarified before, the presence of electric lights outside the dwelling may change the habits of the household members and mostly that of men, as they can now spend more time outside the house after the sunset. The coefficients of the probit regressions do not highlight any significant link for the first two models -negative but not significant coefficients; on the other hand, the probit computed only on the men part of the household evidence a positive and significant influence of using electric lights and malaria occurrence. This result suggests that the exposure channel may work only for the male part of the households but not for all the family members; this result is partly justified by the fact that men are the ones spending more time outside the dwellings in particular after the sun goes down, as that is the time when they gather to play cards, sports or simply chat (Kampango et al., 2011).

In order to check the robustness of the multivariate results, all the six models previously described have been computed using all the malaria cases which have not been confirmed by a health practitioner (there are approximately 2,300 malaria cases out of 5,100 in total which have not been confirmed by a health practitioner). The results, Table 5, do not show any relevant difference with the ones presented in Table 4.

$<$ Table 5 about here $>$

All the links previously highlighted are still valid using the 'non confirmed malaria cases' dependent variables; the interesting result which is worth mentioning is that in all the six models the nexus between the use the electricity -either for cooking and for lighting purposes- 
This is the version of the article accepted for publication in Energy Policy Vol. 101, 310-316 published by Elsevier available at: http://dx.doi.org/10.1016/j.enpol.2016.10.028

Accepted version made available under CC-BY-NC-ND 4.0 License from SOAS Research Online:

https://eprints.soas.ac.uk/23437/

and the occurrence of malaria -at the household level, only for women and only for menappears to be stronger and more significant than when only confirmed cases were considered. Those results can be explained by the fact that the number of non-confirmed malaria cases occurring in an electrified environment is higher than the number of malaria cases confirmed by a health practitioner, hence making the nexus stronger and more significant. At this stage, notwithstanding the fact that the electricity-malaria nexus seems to be positive, it is difficult to exactly establish the magnitude and significance of this positive nexus.

\section{Conclusions and policy implications}

Electrification is without any doubt an important pre-condition needed for the development of both urban and rural areas of developing and transition countries. Its beneficial effects are well known and they range from better health deriving from substituting polluting biomass with a clean energy source, to save time for cooking and collecting firewood, from longer hours for studying reasons to access to television and radio. Alongside with a number of positive consequences electricity may bring, little has been researched over an unintended effect electrification may cause, which is the increased occurrence of malaria cases.

This study aims at presenting descriptive and empirical evidence on the nexus between the electricity use and malaria incidence and to raise the awareness of development practitioners on this issue. The results corroborate the hypothesis that the use of electricity, either via the change in the lifestyle -exposure channel- or via the reduced indoor pollution -vector density channel- does indeed increase the occurrence of malaria among household's members. In particular, the multivariate results indicate that the use of electricity for cooking - vector density channel- affects all the household members, even if women are particularly affected by that 
This is the version of the article accepted for publication in Energy Policy Vol. 101, 310-316 published by Elsevier available at: http://dx.doi.org/10.1016/j.enpol.2016.10.028

Accepted version made available under CC-BY-NC-ND 4.0 License from SOAS Research Online:

https://eprints.soas.ac.uk/23437/

channel. Women commonly spend more time in the kitchen compared to male counterpart and, hence, they are more likely to be exposed to a greater amount of malaria vectors. The exposure channel highlights the fact that using electricity for lighting increases the likelihood of getting malaria only for the male part of the households -adults men and children- with the woman part of the household members not affected by this channel in a significant way.

The policy implications stemming out of this study are multiple considering the fact that Malawi is an extremely poor country with a low degree of households being connected to the grid and where malaria still constitutes an endemic disease. As the electrification rate in the country will soon increase, the central Government should enforce anti-malaria programs and invest in treated bed-nets and education campaigns. These campaigns should be directed to all the household members and they should point out the fact that electricity use may increase malaria occurrence if, at the same time, other measures are not taken into account.

Second, it has to bear in mind that the electricity-malaria nexus may exist in other malaria endemic countries; additional and rigorous studies, preferably using ad-hoc surveys aimed at measuring the sign and the magnitude of the malaria-electricity link, should be carried out there as well. 
This is the version of the article accepted for publication in Energy Policy Vol. 101, 310-316 published by Elsevier available at: http://dx.doi.org/10.1016/j.enpol.2016.10.028

Accepted version made available under CC-BY-NC-ND 4.0 License from SOAS Research Online:

https://eprints.soas.ac.uk/23437/

\section{References}

Ajadi, K. O., Olaniran, H. D., Alabi, F. M., Adejumobi, D. O. (2012). Incidence of malaria among various socio-economic households. Greener Journal of Medical Sciences 2 (3): 51-63.

Aman, M. M., K. H. Solangi, M. S. Hossain, A. Badarudin, G. B. Jasmon, H. Mokhlis, A. H. A. Bakar, and S. N. Kazi. (2015). A review of Safety, Health and Environmental (SHE) issues of solar energy system. Renewable and Sustainable Energy Reviews, 41: 1190-1204.

Barghini, A. and de Medeiros, B. A. S. (2010). Artificial Lighting as a Vector Attractant and Cause of Disease Diffusion, Environmental Health Perspectives, 118: 1503-1506.

Biran, A., Smith, L., Lines, J., Ensink, J., Cameron, M. (2007). Smoke and malaria: are interventions to reduce exposure to indoor air pollution likely to increase exposure to mosquitoes? Transactions of the Royal Society of Tropical Medicine and Hygiene, 101: 10651071.

Chitunhu, S., \& Musenge, E. (2015). Direct and indirect determinants of childhood malaria morbidity in Malawi: a survey cross-sectional analysis based on malaria indicator survey data for 2012. Malaria journal, vol. 14(1), 265.

Dube, F. F., Tadesse, K., Birgersson, G., Seyoum, E., Tekie, H., Ignell, R., \& Hill, S. R. (2011). Fresh, dried or smoked? Repellent properties of volatiles emitted from ethnomedicinal plant leaves against malaria and yellow fever vectors in Ethiopia. Malaria journal, 10(1), 1-14.

Erhart, A., Thang, N., Nguyen, Q. H., Toi, L., Hung, L., Tuy, T., Cong, L., Speybroeck, N., Coosemans, M. and D'Alessandro, U. (2004). Forest malaria in Vietnam: a challenge for control, Am. J. Trop. Med. Hyg., vol. 70(2): 110-118. 
This is the version of the article accepted for publication in Energy Policy Vol. 101, 310-316 published by Elsevier available at: http://dx.doi.org/10.1016/i.enpol.2016.10.028

Accepted version made available under CC-BY-NC-ND 4.0 License from SOAS Research Online:

https://eprints.soas.ac.uk/23437/

GOM Government of Malawi (2011), Department of Climate Change and Meteorological Services: Malawi weather and climate. Government Printing Press, Zomba, Malawi.

Guthmann, J.P., Hall, A.J., Jaffar, S., Palacios, A., Lines, J., Llanos-Cuentas, A. (2001). Environmental risk factors for clinical malaria: a case-control study in the Grau region of Peru. Trans R Soc Trop Med Hyg. 95: 577-83.

Grimm, M., Sparrow, R. and Tasciotti, L. (2015). Does electrification spur the fertility transition? Evidence from Indonesia. Demography, vol. 52(5).

Holtz, T. H., Marum, L. H., Mkandala, C., Chizani, N., Roberts, J. M., Macheso, A., Parise, M. E., Kachur, S.P. (2002). Insecticide-treated bednet use, anaemia, and malaria parasitaemia in Blantyre district, Malawi. Trop Med Int Health. 7: 220-230.

Huldén, L. and McKitrick, R. (2013). Average household size and the eradication of malaria. Journal of the Royal Statistical Society. Series A, DOI: 10.1111/rssa.12036 .

IEA International Energy Agency (2014). Outlook, Africa Energy. A Focus on Energy Prospects in Sub-Saharan Africa-World Energy Outlook Special Report.

Kachur, S. P., Phillips-Howard, P. A., Odhacha, A. M., Ruebush, T. K., Oloo, A. J., Nahlen, B. L. (1999). Maintenance and sustained use of insecticide-treated bed nets and curtains three years after a controlled trial in western Kenya. Trop Med Int Health. 4: 728-735.

Kampango, A., Cuamba, N., Charlwood, J. D. (2011). Does moonlight influence the biting behaviour of Anopheles funestus?. Medical and veterinary entomology, vol. 25(3), 240-246.

Kaygusuz, K. (2012). Energy for sustainable development: A case of developing countries. Renewable and Sustainable Energy Reviews, vol. 16(2): 1116-1126. 
This is the version of the article accepted for publication in Energy Policy Vol. 101, 310-316 published by Elsevier available at: http://dx.doi.org/10.1016/j.enpol.2016.10.028

Accepted version made available under CC-BY-NC-ND 4.0 License from SOAS Research Online:

https://eprints.soas.ac.uk/23437/

Kilpatrick, A. M., \& Randolph, S. E. (2012). Drivers, dynamics, and control of emerging vectorborne zoonotic diseases. The Lancet, vol. 380(9857): 1946-1955.

Kleinschmidt, I. And Sharp, B (2001). Patterns in age-specific malaria incidence in a population exposed to low levels of malaria transmission intensity. Tropical Medicine \& International Health 6(12): 986-991.

NSO National Statistic Office of Malawi (2005). Demographic and Health Survey 2004. Zomba, Malawi and Calverton, Maryland, United States.

Nuwaha, F. (2002). People's perception of malaria in Mbarara, Uganda, Tropical Medicine and International Health, vol. 7: 462-470.

Paul, R. E., Packer, M. J., Walmsley, M., Lagog, M., Ranford- Cartwright, L. C., Paru, R. and Day, K. P. (1995). Mating patterns in malaria parasite populations of Papua New Guinea, Science, vol. 269: $1709-1711$.

Pellegrini, L. and Tasciotti, L. (2012). Rural electrification now and then: comparing contemporary challenges in developing countries to the United States' experience in retrospect, Forum of Development Studies': 1-24.

Pellegrini, L. and Tasciotti, L. (2015). The electrification-malaria nexus: the case of rural Uganda. Forthcoming in 'European journal of Development Research'.

Seyoum, A., Pålsson, K., Kung'a, S., Kabiru, E.W., Lwande, W., Killeen, G.F., Hassanali, A., Knols, B.G.J. (2002). Traditional use of mosquito-repellent plants in western Kenya and their evaluation evaluation in semi-field experimental huts against Anopheles gambiae: ethnobotanical studies and application by thermal expulsion and direct burning, Trans. R. Soc. Trop. Med. Hyg., vol. (96): $225-231$. 
This is the version of the article accepted for publication in Energy Policy Vol. 101, 310-316 published by Elsevier available at: http://dx.doi.org/10.1016/j.enpol.2016.10.028

Accepted version made available under CC-BY-NC-ND 4.0 License from SOAS Research Online:

https://eprints.soas.ac.uk/23437/

Taylor, B. (1997). Malaria transmission-mosquitoes, humans and their behavior. Antenna, vol.

18: $18-22$.

Taylor, T.E. (2009). Caring for children with cerebral malaria: insights gleaned from 20 years on a research ward in Malawi. Trans $R$ Soc Trop Med Hyg., vol. 103(Suppl 1):S6-10. http://dx.doi.org/10.1016/j.trstmh.2008.10.049 .

Winther, T. (2011). The Impact of Electricity: Development, Desires and Dilemmas.

World Bank (2008). The Welfare Impact of Rural Electrification: A Reassessment of the Costs and Benefits An IEG Impact Evaluation, The World Bank, Washington, D.C.

WHO (2012). World malaria report 2012, WHO Press, Geneva, Switzerland.

World Bank. 2015. World Development Indicators -- GDP per capita (current US\$). World Bank national accounts data. Washington, DC: World Bank.

Yamamoto, S., Louis, V.R., Sié, A. and Sauerborn, R. (2010). Household risk factors for clinical malaria in a semi-urban area of Burkina Faso: a case-control study, Transactions of the Royal Society of Tropical Medicine and Hygiene, vol. 104: 61-65.

Zhou, S. F. (2015). The 2015 Nobel Prize in Physiology or Medicine goes to three eminent scientists for their remarkable findings in drug discovery against severe and life-threatening parasitic diseases. Hippocrates Journal of Drug Discovery, 1, 1-5. 